\title{
Perancangan Aplikasi Pengolahan Data Tabungan Siswa pada SMK 1 Kartikatama Metro
}

\author{
Tri Listiana ${ }^{(1)}$ Guna Yanti Kemala Sari Siregar ${ }^{(2)}$ \\ Jurusan Ilmu Komputer, Fakultas Ilmu Komputer,Universitas Muhammadiyah Metro \\ Jl.Gatot Subroto No.100 Yosodadi Kota Metro, Telpon :(0725)42445-Fax(0725)42454 \\ E-mail: gunayanti2017@gmail.com
}

\begin{abstract}
Abstrak
Kehadiran pengolah data dalam masa sekarang ini banyak membawa perubahan, baik dalam dunia usaha, instansi-instansi pemerintah, swasta, maupun bidang-bidang lainnya baik dalam pengolahan data maupun ke akuratan data yang dihasilkan. Kebutuhan akan peningkatan kecepatan dan ketepatan dalam pengolahan data semakin mendesak setiap kalangan agar mampu bersaing dalam peningkatan kuantitas maupun kualitas pelayanan yang diberikan. SMK 1 Kartikatama merupakan sekolah swasta di Kota Metro yang mengajarkan siswanya untuk menabung dimulai dari lingkungan sekolah. Dalam pengelolaan dana tabungan siswa masih dilakukan oleh petugas secara manual dengan mencatat pada buku besar. Hal tersebut sangat beresiko terjadinya kesalahan dalam melakukan pengelolaan data. Peneliti mengusulkan sistem informasi pengolahan data tabungan siswa yang dapat digunakan secara terkomputerisasi. Aplikasi ini dikembangkan dengan menggunakan bahasa pemrograman Borland Delphi 7 dan database MySQL. Metode pengembangan sistem informasi ini menggunakan metode System Development Life Cycle (SDLC) yang secara terstruktur konsep Entity Relationship Diagram (ERD) dan Data Flow Diagram (DFD) digunakan untuk melakukan analisis sistem. Sistem informasi Pengolahan Hasil yang diperoleh dari pengembangan sistem informasi pengolahan data tabungan ini adalah dapat mempercepat laporan data simpanan yang akan dilaporkan kepada wali kelas dan mempercepat proses pencarian data penarikan serta memudahkan petugas dalam pembuatan laporan hasil tabungan siswa.

Kunci : Aplikasi Pengolahan Data, Borland Delphi 7, Data Tabungan Siswa, Perancangan Aplikasi, SMK 1 Kartikatama Metro.

\section{PENDAHULUAN}

Kehadiran pengolah data dalam masa sekarang ini banyak membawa perubahan, baik dalam dunia usaha, instansi-instansi pemerintah, swasta, maupun bidang-bidang lainnya baik dalam pengolahan data maupun ke akuratan data yang dihasilkan. Kebutuhan akan peningkatan kecepatan dan ketepatan dalam pengolahan data semakin mendesak

setiap kalangan agar mampu bersaing dalam peningkatan kuantitas maupun kualitas pelayanan yang diberikan. Kehadiran pengolah data dalam masa sekarang ini banyak membawa perubahan, baik dalam dunia usaha, instansi-instansi pemerintah, swasta, maupun bidang-bidang lainnya baik dalam pengolahan data maupun ke akuratan data yang dihasilkan.
\end{abstract}


SMK 1 Kartikatama merupakan sekolah swasta di Kota Metro yang mengajarkan siswanya untuk menabung dimulai dari lingkungan sekolah. Dalam pengelolaan dana tabungan siswa masih dilakukan oleh petugas secara manual dengan mencatat pada buku besar. Hal tersebut banyak mempunyai kelemahan, antara lain perhitungan berulang-ulang saat pencarian jumlah tabungan per siswa serta sulitnya rekap data yang dilakukan setiap bulan saat akan disetor ke bank. Solusi yang diusulkan untuk menyelesaikan masalah yang ada saat ini adalah dibangun suatu Sistem tabungan siswa untuk memberikan kemudahan pengelolaan tabungan siswa sebelum dan setelah disetor ke Bank.

Hal tersebut sangat beresiko terjadinya kesalahan dalam melakukan pengelolaan data. Peneliti mengusulkan sistem informasi pengolahan data tabungan siswa yang dapat digunakan secara terkomputerisasi. Aplikasi ini dikembangkan dengan menggunakan bahasa pemrograman Borland Delphi 7 dan database MySQL. Metode pengembangan sistem informasi ini menggunakan metode System Development Life Cycle (SDLC) yang secara terstruktur konsep Entity Relationship Diagram (ERD) dan Data Flow Diagram (DFD) digunakan untuk melakukan analisis sistem.

Dengan pengembangan aplikasi pengolahan data tabungan ini diharapkan dapat mempermudah petugas dalam proses pengolahan data tabungan berdasarkan NIS serta dapat mempermudah petugas dalam pembuatan laporan data tabungan siswa.

\section{KAJIAN PUSTAKA DAN LANDASAN TEORI 2.1 Pengertian Perancangan}

Ada beberapa pengertian perancangan menurut beberapa ahli. Menurut Susanto yang dikutip oleh Dedynggego, dkk, (2015:47) "perancangan adalah spesifikasi umum dan terinci dari pemecahan masalah berbasis computer yang telah dipilih selama tahap analisis". Sedangkan menurut Febrian yang dikutip oleh Rianto dkk, (2015:296) mendefinisikan bahwa, rancangan merupakan tahap dan keperluan atau yang telah dianalasis kedalam bentuk yang mudah dimengerti oleh pemakai (user), ada tiga atribut yang penting dalam proses perancangan yaitu struktur data, arsitektur perangkat lunak dan prosedur perinci.

Definisi perancangan menurut Soetam Rizky yang dikutip oleh Ackbar Rianto, Setiawan Assegaf, dan Erik Fernando (2015:296) "perancangan adalah sebuah proses untuk mendefinisikan sesuatu yang akan dikerjakan dengan menggunakan teknik yang bervariasi serta didalamnya melibatkan deskripsi mengenai arsitektur serta detail komponen dan juga keterbatasan yang dialami dalam proses pengerjaannya". Definisi perancangan menurut Bambang Hariyanto yang dikutip oleh Rianto, (2015:296) "Perancangan merupakan penghubung antara kebutuhan dan implementasinya"..

\subsection{Pengertian Aplikasi}

Aplikasi menurut Jogiyanto yang dikutip oleh Ahmad Budiman dan Asri Mulyani (2016:375) “Aplikasi adalah penggunaan dalam suatu perangkat komputer, intruksi (instruktion) atau pernyataan (statement) yang disusun hingga sedemikian rupa. Komputer dapat memproses masukan (input) menjadi keluaran (output)". 


\subsection{Pengertian Pengolahan Data}

Menurut Jogiyanto Hartono yang dikutip oleh Arman (163) Mendefinisikan bahwa, pengolahan (processing) adalah proses data yang diolah melalui suatu model menjadi informasi, penerima kemudian menerima informasi tersebut, membuat suatu keputusandan melakukan tindakan, yang berarti menghasilkan suatu tindakan yang lain yang akan membuat sejumlah data kembali. Data tersebut akan ditangkap sebagai input, diproses kembali lewat suatu model dan seterusnya membentuk suatu siklus. Siklus ini disebut juga dengan siklus pengolahan data (Data Processing Cycles).

\subsection{Pengertian Tabungan}

Tabungan merupakan salah satu dari berbagai macam produk perbankan yang paling banyak diminati oleh masyarakat, mulai dari kalangan pelajar, kalangan pengusaha, dan masyarakat umum lainnya. Sebelum adanya perbankan masyarakat menyimpan uangnya dirumah, seperti di lemari maupun dibawah kasur. Dan dengan penyimpanan yang seperti itu sangat tidak efektif, karena memiliki resiko kehilangan yang tinggi. Dengan adanya perbankan yang menyediakan produk tabungan masyarakat sudah mulai tertarik untuk menabung dibank karena banyak keuntungan yang diperoleh, antara lain uang yang disimpan aman dan uang nasabah akan bertambah dengan adanya bunga bank.

Menurut UU No 10 Tahun 1998 yang dimaksud dengan tabungan adalah simpanan yang penarikannya hanya dapat dilakukan menurut syarat-syarat tertentu yang disepakati, tetapi tidak dapat ditarik dengan cek, bilyet giro, dan atau alat lainnya yang dipersamakan dengan itu, sedangkan tujuan dari menabung adalah mengumpulkan dana dari masyarakat guna membiayai pembangunan dan menanamkan kebiasaan menabung dikalangan masyarakat.

\subsection{Perancangan Sistem}

\section{Borland Delphi 7}

Menurut definisi irnawan, S.Kom yang berjudul (2006,:1) Delphi adalah suatu bahasa pemograman (development language) yang digunakan untuk merancang suatu aplikasi program. Borland Delphi dapat digunakan untuk membuat aplikasi windows, merancang aplikasi program berbasis grafis, membuat program berbasing jaringan (client/server) dan membuat program Net (berbasis internet).

Keunggulan dari penggunaan Delphi antara lain, IDE (Integrated Development Environment) atau lingkungan pengembangan aplikasi sendiri adalah satu dari beberapa keunggulan Delphi, didalamnya terdapat menu-menu yang memudahlan kita membuat sesuatu proyek program, proses kompilasi cepat, pada saat aplikasi yang kita buat dijalankan pada Delphi, maka secara otomotis akan dibaca sebagai sebuah program, tanpa dijalankan terpisah serta mudah digunakan.

\section{$M y S Q L$}

Menurut Bunafit Nugroho (2005,:1) adalah sebuah program database server yang mampu menerima dan mengirimkan datanya dengan sangat cepat, multi user serta menggunakan perintah standar SQL (Structured Query Language). MySQL memiliki dua bentuk lisensi, yaitu FreeSoftwere dan Sharewere. MySQL yang biasa kita gunakan adalah MySQL FreeSoftwere yang berada dibawah lisensi 
GNU/GPL (General Public License). Keterangan lengkap dapat dilihat pada http://www.gnu.org//licenses/. Selain itu anda juga dapat memiiki produk MySQL yang sifatnya komersial, biasa disebut dengan MySQL AB.

\section{QuickReport}

Quick Report merupakan salah satu komponen yang ada dalam Borland Delphi 7 yang berfungsi untuk memberikan laporan kepada user berupa print out mengenai sebuah program. Quick Report akan sangat berguna apabila sebuah program membutuhkan laporan. Laporan bisa dibuat berupa laporan harian, mingguan, atau bulanan yang akan sangat membantu dalam proses bisnis dalam sebuah organisasi atau perusahaan.

\section{METODE}

Metode pengembangan aplikasi pada penelitian ini menggunakan metode penelitian System Development Life Cycle (SDLC). SDLC digunakan untuk membangun suatu sistem informasi agar dapat berjalan sesuai dengan apa yang diharapkan. SDLC juga merupakan pola yang diambil untuk mengembangkan sistem perangkat lunak, yang terdiri dari tahap-tahap: perencanaan (Planning), Analisis (Analysis), desain (Design), implementasi (implementation), uji coba (testing) dan pengelolaan (maintenance).

Dalam proses pengumupulan data, ada dua metode yang dilakukan yaitu Studi Lapangan dan Studi Pustaka.

\section{Studi Lapangan}

Studi lapangan adalah pengumpulan data yang secara langsung mempelajari yang berkaitan dengan masalah-masalah yang sedang dihadapi. Adapun studi lapangan yang penulis lakukan adalah dengan teknik: a. Pengamatan (Observation).

Penelitian secara langsung pada SMK Kartikatama 1 metro, sehingga penulis dapat mengetahui secara langsung tentang alur sistem pekerjaan yang sedang berjalan saat ini.

b. Wawancara (interview).

c. Penulis melakukan tanya jawab secara langsung dengan Bapak Fuad Mardi Al Rosyid selaku ketua tabungan siswa SMK Kartikatama 1 metro.

d. Dokumentasi (Documentation).

Penelitian yang dilakukan dengan mengumpukan dokumentasi informasi yang ada pada SMK Kartikatama untuk kelengkapan pengumpulan data

\section{Studi Pustaka}

Studi pustaka yaitu proses pengambilan data dengan mempelajari literatur maupun artikel yang berkaitan dengan perancangan aplikasi, database serta unsur-unsur sehingga dapat memperlancar pelaksaan penulis masalah yang dihadapi.

\section{HASIL DAN PEMBAHASAN}

Dalam melakukan penelitian pada SMK 1 Kartikatama Metro, penulis menemukan adanya kekurangan dalam proses pengolahan data tabungan siswa. Sistem pengolahan data tabungan siswa pada SMK Kartikatama Metro yang masih menggunakan buku besar dalam pencarian data tabungan siswa masih mengalami kesulitan karena harus mencari nama satu per satu, sehingga menyebabkan keterlambatan pada proses cetak laporan tabungan siswa. Agar hasil penelitian yang dilakukan tidak menyimpang dari permasalahan, penulis membatasi ruang lingkup penelitiannya antara lain pengolahan data tabungan siswa menggunakan bahasa 
pemograman Borland Delphi 7 dan database mysql, cetak laporan berdasarkan nis menggunakan quick report, pencarian data tabungan siswa berdasarkan NIS.

\subsection{Perancangan Aplikasi}

Tujuan perancangan sistem ini adalah untuk menganalisis aplikasi pengolahan data tabungan siswa pada SMK 1 Kartikatama Metro. Perancangan ini diusulkan sebagai bahan masukkan yang dapat di pertimbangkan untuk meningkatkan efektifitas kerja khususnya untuk pengolahan data tabungan siswa. Tujuan perancangan sistem ini menggunakan bahasa pemograman Borland Delphi 7, database dan table menggunakan MySQL sebagai penyimpanan, dapat melakukan pencarian data tabungan berdasarkan NIS, pembuatan laporan menggunakan QuickReport berdasarkan NIS agar dapat lebih cepet dan akurat.

\section{Rancangan Flowchart}

Flowchart adalah suatu bagan dengan simbol-simbol tertentu yang menggambarkan urutan proses secara mendetail dan hubungan antara suatu proses (intruksi) dengan proses lainnya dalam suatu program. Flowchart untuk penelitian ini dapat dilihat pada Gambar 1.

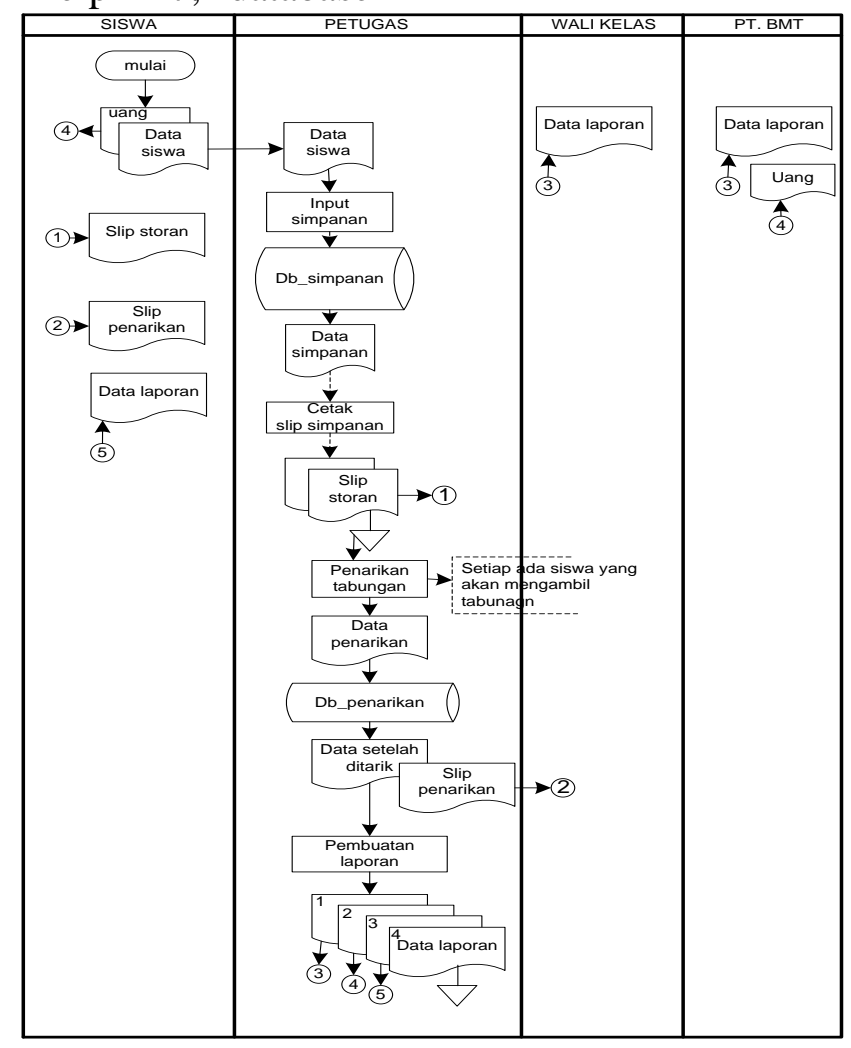

Gambar 1. Flowchart usulan sistem

\section{Rancangan Diagram Context}

Data Flow Diagram (DFD) adalah suatu Diagram yang menggunakan notasi-notasi untuk menggambarkan arus dari data pada suatu sistem, yang penggunaannya sangat membantu untuk memahami sistem secara logika, terstruktur dan jenis. Rancangan Diagram Context pengolahan data tabungan siswa dapat dilihat pada Gambar 2 


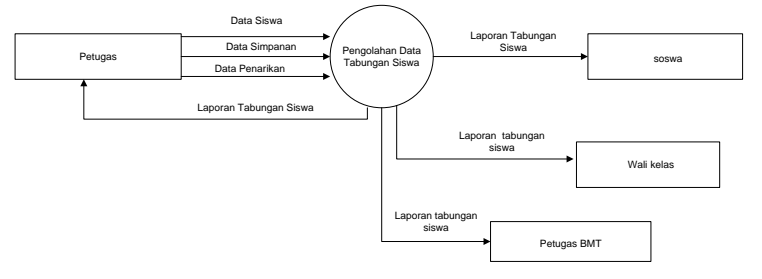

Gambar 2. Diagram Context usulan sistem

Data Flow Diagram (DFD) adalah suatu diagram yang menggunakan notasi-notasi untuk menggambarkan arus data pada suatu sistem, yang penggunaannya sangat membantu untuk memahami sistem secara logika, terstruktur dan jelas. Rancangan Data Flow Diagram pengolahan data DFD (Data Flow Diagram) tabungan siswa dapat dilihat seperti pada Gambar 3.

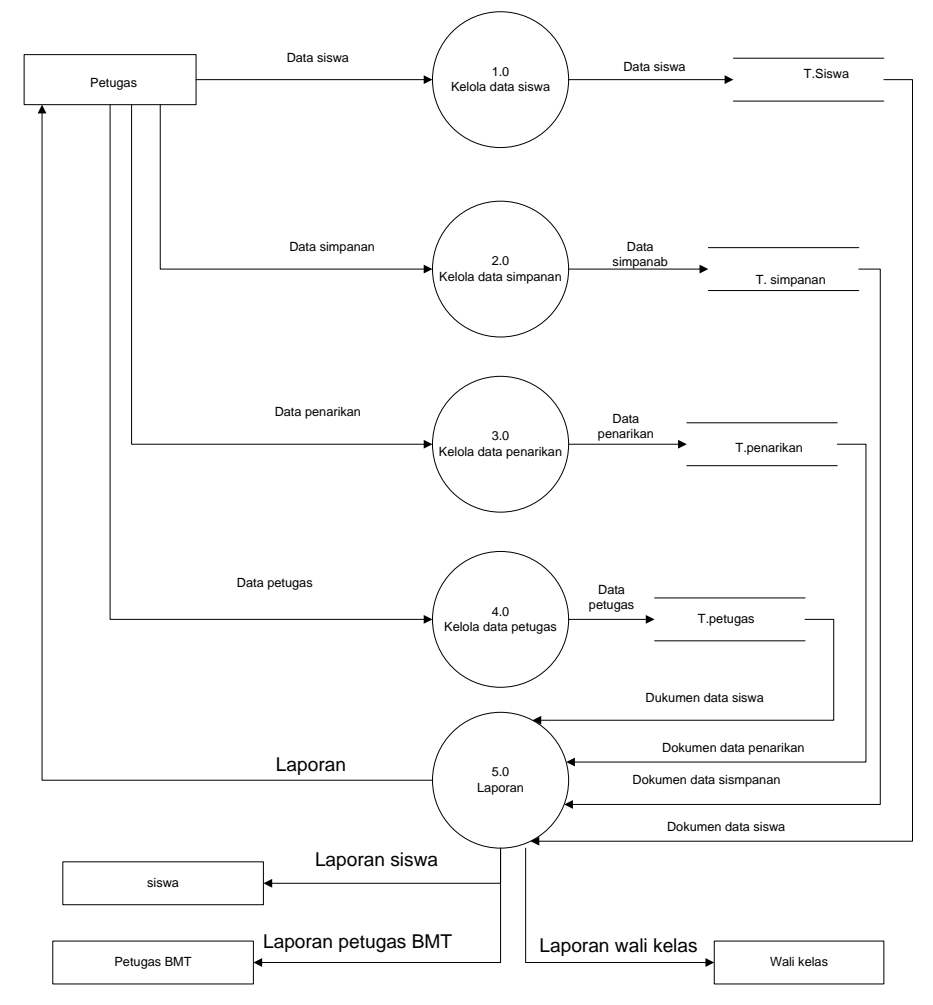

Gambar 3. Data Flow Diagram

ERD (Entity Relationship Diagram)

Entity Relationshop Diagram adalah alat pemodelan data utama dan akan membantu mengorganisasi data dalam satu proyek kedalam entitas-entitas dan menentukan hubungan antar entitas. Proses memungkinkan analisis menghasilkan struktur basis data yang baik sehingga dapat disimpan dan diambil secara efisien yang dapat dilihat pada Gambar 4. 


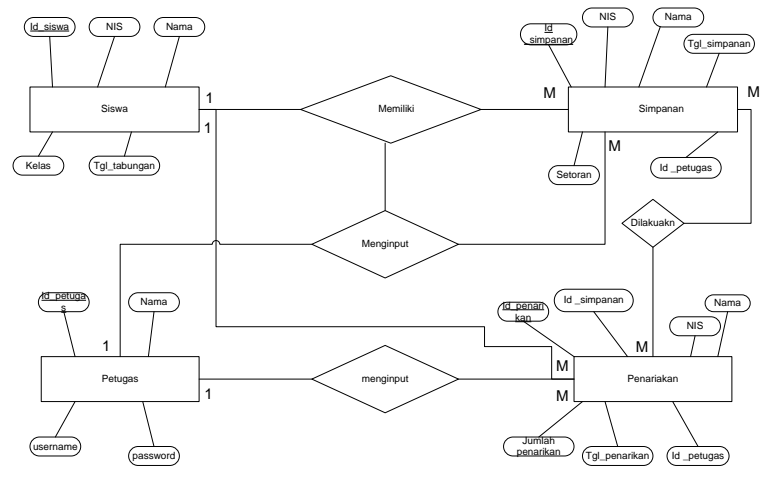

Gambar 4. ERD

\section{Relasi Tabel}

Hubungan sebuah table dengan table lainnya. Sehingga tabel tidak lagi berdiri sendiri, melainkan dapat dihubungan kan antara satu dengan yang lainnya dan menjadi satu kesatuan. Ada dua buah kolom yang diperlukan untuk menghubungkan sebuah tabel dengan tabel lainnya. Adapun rancangan database dapat dilihat pada relasi tabel pada gambar 5

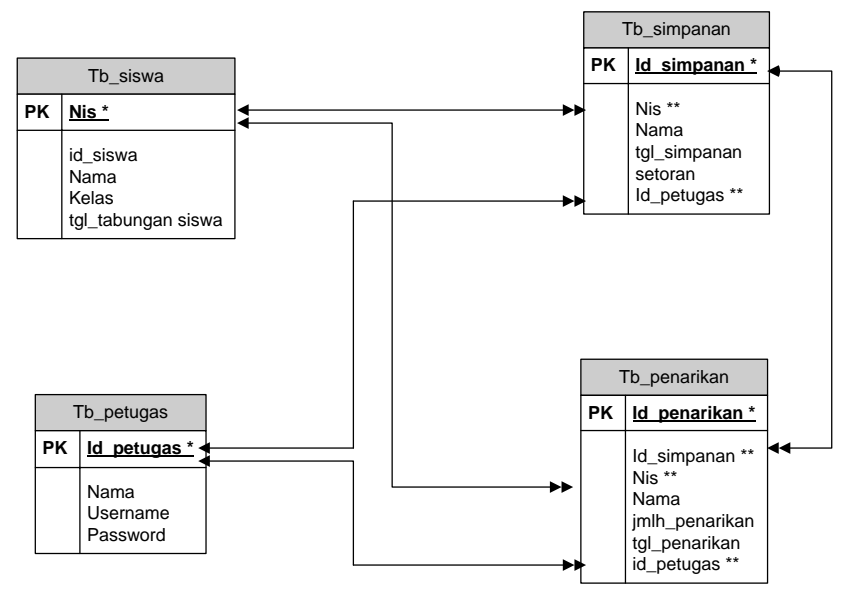

Gambar 5. Relasi Tabel

\subsection{Hasil Pengembangan Sistem}

\section{Tampilan Login}

Tampilan Form Login ini berfungsi sebagai tempat untuk memasukkan username dan password saat akan melakukan input data siswa. Adapun menu utama dapat dilihat pada Gambar 6.

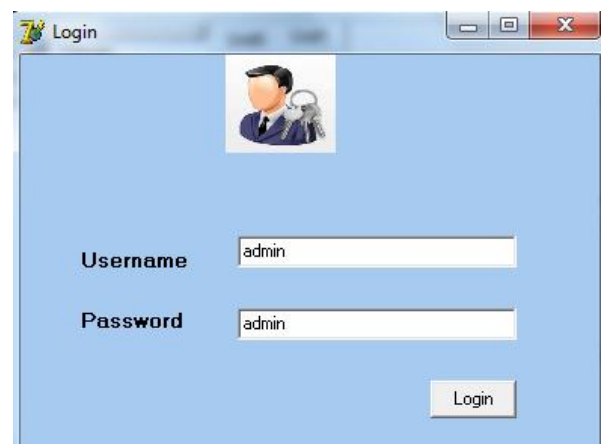

Gambar 6. Tampilan Login

\section{Tampilan Halaman Utama}

Tampilan halaman utama berfungsi sebagai tampilan sebagai tampilan awal aplikasi pengolahan data tabungan siswa dan uang. Adapun menu utama dapat dilihat pada gambar 7.

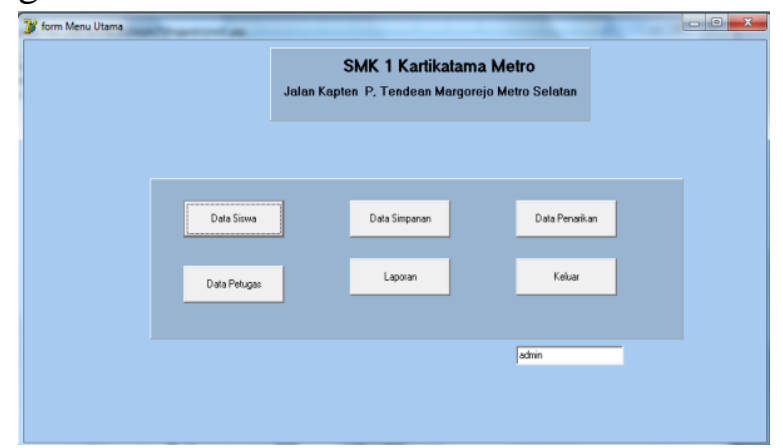


Gambar 7. Tampilan Halaman Utama

\section{Form Input}

Ada 3 form input yang disediakan oleh aplikasi ini, yaitu Form input Data Mahasiswa (Gambar 8), Form input Data Simpanan (Gambar 9), Form input Data Penarikan (Gambar 10), dan Form input Data Petugas (Gambar 11).

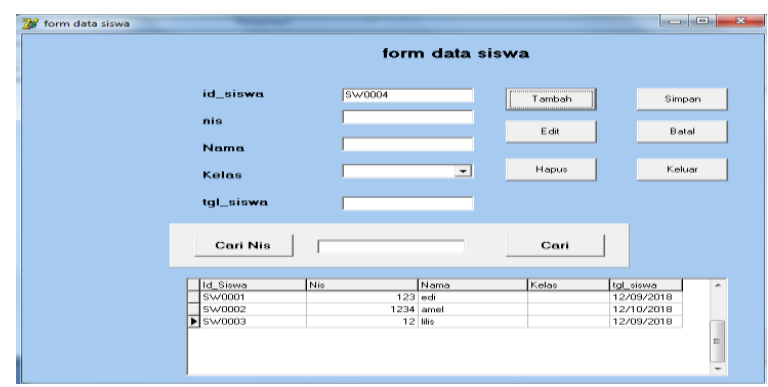

Gambar 8. Form Input Data Mahasiswa

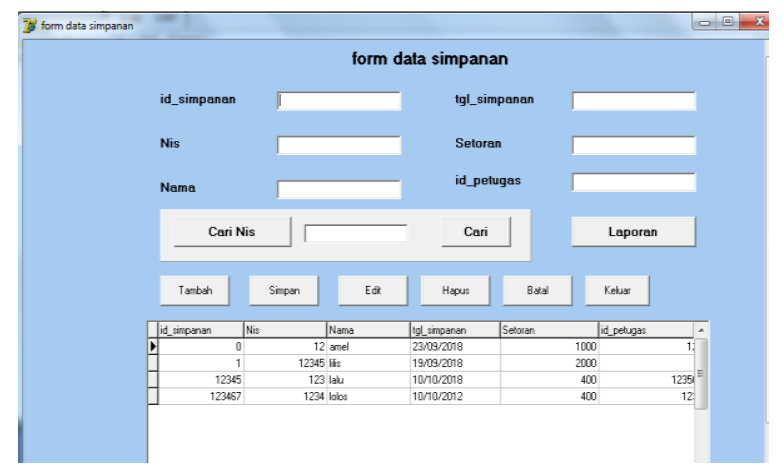

Gambar 9. Form Input Data Simpanan

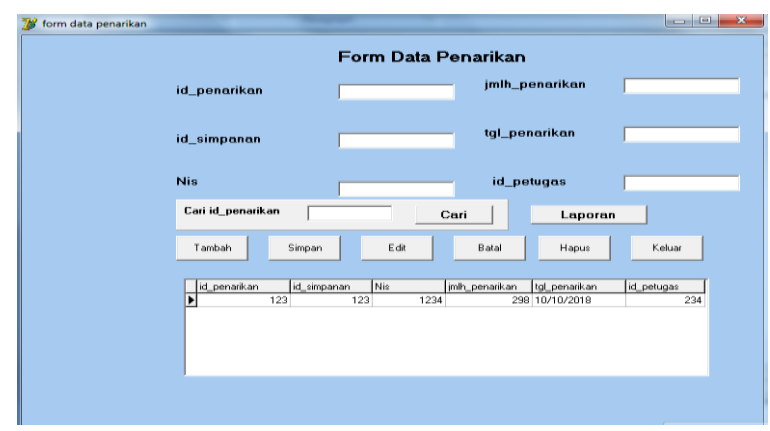

Gambar 10. Form Input Data Penarikan

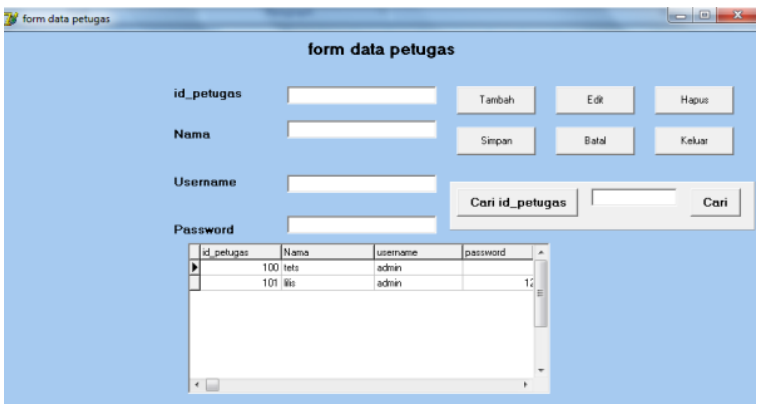

Gambar 11. Form Input Data Petugas

\section{Form Output}

Form tampilan output/cetak Laporan Data Simpanan, berfungsi sebagai hasil akhir inputan yang dilakukan oleh admin untuk dijadikan sebagai laporan Data Simpanan siswa SMK 1 Kartikatama Metro. Adapun form output data simpanan dapat lihat pada gambar 12

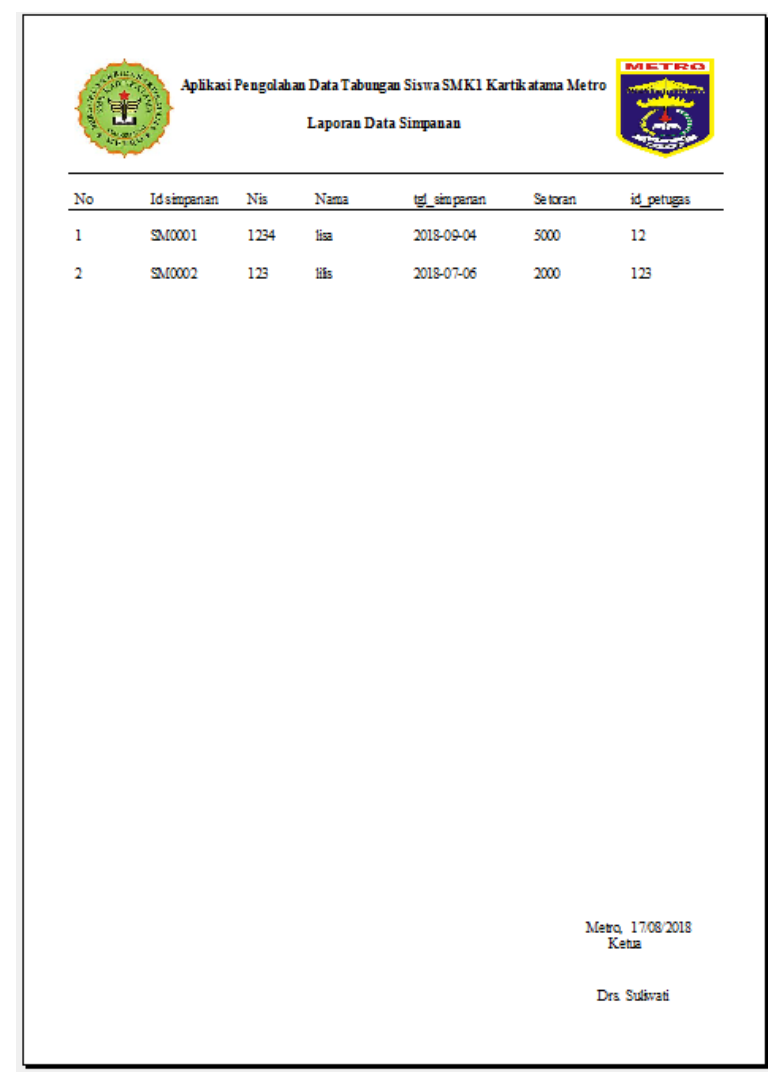

Gambar 12. Laporan Data Simpanan 


\subsection{Pengujian Sistem}

Berdasarkan hasil pengembangan aplikasi Pengelolaan Data Tabungan SMK 1 Kartikatama Metro. Adapun kelebihan dan kekurangan program yang diperoeh dari umpan balik pihak sekolah adalah sebagai berikut.

\section{a. Kelebihan Program}

- Dengan menggunakan aplikasi pengolahan data siswa dapat mempercepat pencaraian data.

- Mempermudah pembuatan laporan data siswa dan data tabungan siswa.

- Dapat menyimpan file dalam jumlah cukup besar.

\section{b. Kekurangan}

Program aplikasi ini hanya dapat dibuka pada operasi system berbasis windows. Program aplikasi ini tidak berbasis online

\section{KESIMPULAN}

Dengan menggunakan aplikasi yang baru, pengolahan data tabungan siswa dapat meningkatkan kinerja petugas diantaranya adalah sebagai berikut:

1. Memperbaiki pengolahan data tabungan siswa pada sekolah SMK 1 Kartikatama Metro.

2. Mempercepat laporan data simpanan yang akan dilaporkan kepada wali kelas dan Mempercepat proses pencarian data penarikan pada sekolah SMK 1 Kartikatama.

3. Dengan adanya aplikasi pengolahan data tabungan siswa akan memudahkan dalam pembuatan laporan hasil tabungan siswa.

\section{DAFTAR PUSTAKA}

Ahmad Budiman dan Asri Mulyani 2016. Rancang Bangun Aplikasi Sistem Informasi Persedian Barang diTB, Indah Jaya Berbasis Desktop. Jurnal Algoritma Sekolah Tinggi Teknologi Garut (2016): 375

Budi Serasi Ginting,S.Kom.,M.Kom. dan Drs.Hermansyah Sembiring,M.Kom 2013. Sistem informasi tunggakan premi nasabah menggunakan pemograman visual Delphi pada asuransi jiwa bersama bumi putera 1912 cabang binjai. Vol.7 No.1(2013): 30

Irnawan. 2006. Memahami Pemograman Delphi 7.Jakarta: BSI PRESS

Bunafit Nugroho. 2005. Database Relasional dengan MySQL. Yogyakarta: ANDI

Janner Simarmata dan Imam Paryudi. 2006,2010. Basis Data. Yogyakarta: C.V ANDI OFFSET

Putra, dkk. Aplikasi Penjualan dan Pemasaran Berbasis Web Pada CV Suasana Indah Profil

Fathansyah, Ir. (1999). "Basis Data". Informatika Bandung

Rohmadi. (2008). "Perancangan Basis Data Sistem Informasi Pelayanan Medis Rumah Bersalin Permata Hati Abadi Sragen". Jurnal Kesehatan Maret 2008. Sragen

Henda. (2013). "Analilis dan Perancangan Sistem Basis Data Penjualan dan Pembelian pada CV Edison Prima Pagaralam". Jurnal Ilmiah Februari 2013.Palembang

Erick. (2012). "Analisis dan Peracangan Sistem Basis Data untuk mendukung Aplikasi Penjualan pada PT.Ricky Musi Wijaya Palembang”. Jurnal Ilmiah April 2012.palembang. 
Jurnal Mahasiswa IImu Komputer (JMIK)

Vol. 01, No. 02, Oktober 2020

Kadir , Abdul. (1998). "Konsep dan

Tuntunan Praktis Basis Data". Andi offset Yogyakarta 